\title{
A Fundação - Empresa
}

MANOEL DE OLIVEIRA FRANCO SOBRINHO

Professor Catedrático na Faculdade de Direito da

Universidade Federal do Paraná

Não obstante as incertezas políticas que são constantes na evolução do processo histórico, não há como não entender 0 aperfeiçoamento das técnicas administrativas no que diz respeito com a problemática estatal da Administração.

Não basta ao Estado estar organizado politicamente. Precisa muito mais: é necessário que esteja harmonizado com a Administração e dela faça sua expressão de vontade legal, capaz de atender o serviço público na variada peculiaridade com que se apresenta para satisfação de exigências coletivas.

A isso chamaríamos de racionalização. Tanto o processo histórico, como o jurídico ou o político, fazem uma mesma estrutura organizacional. Harmonizam-se face à realidade e com relação aos fins. A realidade corresponde ao fato. Os fins são aqueles que afetam de momento a sociedade politicamente organizada.

$\S 10$ - REALIDADE E FINS

Quanto ao fato envolve, nas suas perspectivas, elementos integrativos de ordem social e segurança política. Quanto aos fins aumentam na proporção do complexo das atividades inerentes à satisfação das comunidades, obrigando o Estado à adoção de procedimentos que ampliam a conceituação de serviço público.

blicem dizendo, para o Estado moderno, tudo é serviço púdireit A própria defesa do homem, como cidadão sujeito de direito, é função e atribuição do poder estatal através da Administração. Pode ser que sejam diferentes os regimes políticos, mas não são diferentes os métodos especificos de atuafão administrativa.

lidade porque, não ser mais possivel, distinguir onde a readade social não distingue, para estabelecer critérios teóricos 
que afastem o elemento público do elemento de direito privado, tornando estanques situações que se complementam ou situações que se completam pela evidência da unidade na ordem juridica.

Valiosas são, por isso, as contribuições do processo e das leis privadas, civis e comerciais, no sentido da fixação de certos problemas que na sua essência são problemas de natureza pública. Os problemas de fins públicos que se realizam nos limites da esfera privada sem perderem os objetivos de direito público.

\section{§ $2^{\circ}$ - AUTONOMIA APENAS DOUTRINARIA}

Não digam que hoje em dia, por força dos sistemas socializantes, pode o Estado separar o interesse público do interesse privado, adotando posições contrastantes, com a ordem jurídica integrada. Os que assim teimam esquecem o valor da ordem econômica como base da ordem jurídica e conexa da ordem social.

Aquela marcha do direito para a individualização dos seus quadros normativos não prevalece mais como determinação científica. É válida apenas no domínio da doutrina e das especulações teóricas. Ou é apenas válida para conhecimento de certos fenômenos particulares que somados fazem parte de um todo absoluto e real.

Esse todo é o direito. Não o direito civil ou comercial. Não o direito penal ou processual penal. Não o direito internacional público, privado ou político. Não o processual civil ou o direito financeiro. Não o direito constitucional e administrativo. Mas 0 direito como expressão da conduta humana, política e social.

Quando a Administração, pelo Estado, usa das normas civis, buscando o apoio do Código Civil, nada mais faz que reconhecer meios existentes de efetivação de fins comuns ao próprio direito. Pouco importa, diante do objetivo colimado, a natureza do procedimento ou os peculiares métodos jurídicos adotados.

Enorme é a contribuição do Direito Civil para a formação do Direito Administrativo. Quase todas, senão todas, as instituições de Direito Administrativo foram buscadas ou senão inspiradas pelo Direito Civil. Somente pelo Estado, como organização política, o direito se torna material e também positivo.

Já vai distante o tempo das longas e fastidiosas disputas entre posições de civilistas e publicistas. Inclusive para dizer 
aos administratistas que o Direito Administrativo não se deixa fechar nos limites de uma autonomia doutrinária que pretende a separação irreal de pessoas, coisas e fenômenos.

Houve época em que se falava de um Direito Civil publicizado. Não se fala mais. O que valem são os relacionamentos jurídicos que fazem a espécie da pessoa jurídica. Ou a pessoa jurídica criada pelo Estado como a melhor capaz de absorver determinadas situações à realização de certo serviço público essencial.

E o caso aqui das fundações, pessoas jurídicas de direito privado, criadas com a finalidade de direito público. E também o exemplo das empresas públicas, pessoas jurídicas de direito privado, organizadas com o intuito manifesto de atendimento de serviços em áreas econômicas de justificado interesse estatal.

\section{$\S 33^{\circ}$ - OS INSTRUMENTAIS DE DIREITO PRIVADO}

Importa muito, porém, principalmente para o Direito Administrativo, no que diz com a vontade legal da Administração, saber que ele não desmerece os importantes instrumentos que The são oferecidos pelo Direito Privado, sem forçar, no entanto, distinções de sistema, de procedimento ou de conflito de normas.

Porque essa distinção não existe na realidade do direito, seja público ou privado. O que existem são procedimentos ou processos que mais de perto se coadunam com a problemática administrativa. E que dão à Administração elementos jurídicos com que possa cumprir os seus inalienáveis fins de serviço público.

Ninguém discute a imprecisão dos elementos componentes do processo desapropriatório. Como instituto, a desapropriação, tanto poderia pertencer ao Direito Civil como ao Direito Administrativo. Pertence ao Direito Administrativo ou como tal é aceita, tendo em conta os interesses que levam o Estado a desapropriar.

No ato administrativo, no contrato, o que observamos no fundo é a característica lógica da norma civil. De igual maneira nas fundações criadas pelo poder público. Ou nas emPresas, que nominadas de públicas, como pessoas privadas, dão à Administração capacidade no atendimento de serviços públicos antes estatais.

Em se tratando da forma jurídica das empresas públicas, impossivel não considerar a natureza atribuída de caráter de 
pessoa privada, em razão da vontade legislativa cuja importância transcende a hermenêutica. Não cabe ao jurista levantar suspeições interpretativas onde a lei diz ao que vem e 0 que pretende.

Não é somente uma questão de origem ou de fundamentação legal, legislativa. Trata-se, sobretudo, de uma questão de fato, real na estrutura administrativa, indispensável à Administração ativa, quando descentralizada, quando indireta. Principalmente, com respeito ao Estado econômico, ao homem econômico.

Nada há, pois, a admirar, nem a surpreender, com essa nova ou atual tipificação, de fundações e de empresas públicas. Assumem, na verdade, aspectos jurídicos não tradicionais, em virtude da expansão dos fins estatais e da necessidade que - Estado tem para o exato cumprimento de fundamentais exigências econômicas.

Ressalte-se, que depois das sociedades de economia mista, crescem de importância as fundações e as empresas públicas. Com apoio nos instrumentos fornecidos pelo Direito Privado quanto à forma e ao processo. Mas com as implicações de fim, de finalidade, que dão conteúdo às pessoas que fazem serviço público.

\section{§ 4ㄴ - FUNDAÇÃO E EMPRESA PÚBLICA}

Numa tendência que se generaliza, assentada não somente nas práticas administrativas racionais, já se entende poderem as fundações assumir a forma de empresa. Ou as empresas, sem quebra do sistema, assumir a forma de fundação. Isto porque o Estado tem por obrigação procurar os meios mais adequados de administração.

Está no próprio contexto da ordem jurídica essa franquia legal que se exterioriza no serviço público pela determinaçăo das pessoas jurídicas. Sabe o. Estado, dentro da própria organização administrativa, o que melhor convém aos propósitos da Administração, no tocante à execução indireta dos serviços
públicos.

Não há porque, então, não possa a fundação trazer na sua estrutura a forma de empresa. E a recíproca também é verdadeira. Motivos não existem, para que as empresas públicas não se criem como fundações. São ambas sociedades constinuídas com respeito ao princípio da legalidade e à disciplina
orgânica estatal. 
A excessiva privativação da atividade econômica, mercantil e industrial sempre foi um permanente obstáculo para que 0 Estado na extensão pudesse devidamente cumprir os seus fins essenciais de vida. Como fato histórico, no direito, o fenômeno é racionalizador e se justifica pela necessidade pública e social.

Do ponto de vista jurídico e organizacional o problema não é tão complexo como parece: a via adotada é a da descentralização administrativa no terreno econômico, utilizada para instrumento na criação de empresas e fundações, com a finalidade, em regime específico, de assegurar o desenvolvimento planificado.

\section{$\S 55^{\circ}-$ AS NOVAS FÓRMULAS ADEQUADAS}

As empresas públicas, tal como se apresentam hoje no Direito Administrativo, fazem um fenômeno universal cujos antecedentes correspondem ao período posterior à segunda guerra mundial, e cuja problemática envolve a dimensionada e direta ação empresarial do Estado pela Administração. ${ }^{1}$

No sentido próprio dessa problemática estatal, neutralizando a tradição do laissez-faire, laissez-passer sempre constante, sem quebra do respeito pela liberdade econômica, realizam as empresas públicas como também as fundações, a melhor planificação administrativa em relação à competência descentralizadora do Estado.

Impossivel desconhecer que a Administração, ou mesmo - Estado, está comprometida com a segurança da ordem jurídica e pública econômica, impondo-se-lhe a necessidade da sua presença em todas as fronteiras do desenvolvimento, seja de atividade monopolizadora, de produção industrial ou de reguladora do comércio.

A falta de instituições peculiares ou de regras de direito público harmonizadas com a prática do comércio e o exercício da indústria, levam o Estado a procurar no campo do direito privado as fórmulas adequadas melhor condizentes com a evolução reconhecida daqueles serviços públicos chamados essenciais. ${ }^{2}$

tân O papel relevante das autarquias, marcado na sua importancia pela descentralização institucional, onde a orientação

Pǘ 1 Alfonso Perez Moreno - LA FORMA JURIDICA DE LAS EMPRESAS UBLICAS - Introdución - Sevilha, 1969.

${ }^{2}$ Ver Urbano Valero Agundez - LA FUNDACIÓN COMO FORMA DE EMPRESA - Valladolid, 1969. 
de pensamento está forjada em abundante literatura, não deixa dúvidas com respeito a novos fenômenos integrativos racionalizantes, como o da amplitude descentralizadora e o da desconcentração.

Com as autarquias, exaustivamente estudadas no Brasil, não somente se obteve em certos setores magníficos resultados econômicos e administrativos, como se permitiu que a Administração normalmente alargasse dimensões próprias ao entendimento político do Estado moderno, jurídico e técnico ao mesmo tempo.

Não fosse o serviço público da essência estatal, não surgisse o Estado na sua figuração política como uma síntese, não estivesse a economia condicionada pela influência da racionalização técnica, quem sabe as autarquias não oferecessem solução para os problemas vinculados ao desenvolvimento social e econômico. ${ }^{3}$

Chegando a vez das fundações, fácil estaria de prever, que a política do Estado voltasse a se interessar pelas empresas, não só tendo em mira a desburocratização das tarefas administrativas, como a urgência de dar ao poder público instrumentos afins e jurídicos, de conformação do Estado com a realidade econômica. ${ }^{4}$

\section{$\S 60^{\circ}$ - AS EMPRESAS PÚBLICAS}

Estranhe-se, apenas, que ainda não hajam para as empresas públicas, na legislação comparada, leis ou estatutos que se apresentem harmônicos como normas gerais e reguladoras. No Brasil, como sabemos, só ultimamente as empresas vêm preocupando o poder público, possibilitando a vigência de uma legislação ainda não institucionalizada.

3 Na literatura brasileira: Tito Prates da Fonseca - AUTARQUIAS ADMINISTRATIVAS - S. Paulo, 1935; Luis Delgado - AUTARQUIAS - Recife, 1940; Erimá Carneiro - AS AUTARQUIAS E AS SOCIEDADES DE ECONOMIA MISTA - Rio de Janeiro, 1941; A. Nogueira de Sá - DO CONTROLE ADMINISTRATIVO SOBRE AS AUTARQUIAS - Rio de Janeiro, 1952; e Celso Antonio Bandeira de Mello - NATUREZA E REGIME JURÍDICO DAS
AUTARQUIAS - S. Paulo, 1967.

$4 \mathrm{Na}$ literatura estrangeira: H. Laufenburger - INTERVENCIÓN DEL ESTADO EN LA VIDA ECONÓMICA - México, 1945; Brewer Carias - LAS EMPRESAS PÚBLICAS EN EL DERECHO COMPARADO - Caracas, 1967; F. Garrido Falla - ADMINISTRACIÓN INDIRETA DEL ESTADO Y DESCENTRALIZACIÓN FUNCIONAL - Madrid, 1950; e M. Despax - L'ENTERPRISE ET LE DROIT - Paris, 1957. 
$\mathrm{Na}$ diversidade de motivações, ou por motivo de variedade na atuação empresarial, as formas jurídico-administrativas se confundem em função das circunstâncias. Os critérios jurídicos nem sempre podem ser os mesmos, pois variam face o que constitucionalmente se possa chamar de ordem econômica e social.

\section{Dou razão a ALFONSO PEREZ MORENO:}

- "En nuestros dias, la consagración de la técnica planificadora, imponiendo la necesidad de buscar correctivos a las aludidas distorsiones en los órdenes político, económico y jurídico, han determinado el auge de los critérios racionales para dominar el fenómeno, la búsqueda de guias ordenadoras en la elaboración científica operando sobre los datos, ciertamente moldeables, que la realidad histórica de las empresas públicas oferecen." ${ }_{5}$

Nada mais certo. De longa data surgem as empresas públicas aparecendo como solução estatizadora. A influência do Estado, sempre presente, impôs fisionomia diferente tanto em Portugal, como na França ou na Espanha. Na França, a exemplo, por largo tempo, o Estado foi o único empresário no comércio exterior e só por sua iniciativa se criaram as grandes companhias.

A experiência inglesa define os elementos característicos de ordem jurídica e política, marcando por etapas o sentido da revolução das formas de empresa durante o mercantilismo, atribuindo personalidade jurídica às companhias por ações cuja orientação assentava na iniciativa privada. ${ }^{6}$

Precisamente do ensinamento histórico estão se formando as modernas empresas públicas: se por um lado permanecem elas com toda a mecânica inerente aos métodos das organizafões de iniciativa privada, por outro lado se apresentam com ampla capacidade para atuar como sujeito de direitos e obrigações públicas.

Tudo depende, no direito interno, do sistema de estruturação da organização administrativa: estruturação que naturalmente envolve o planejamento, a centralização e a capacidade descentralizadora, a descentralização funcional e a desconcentração administrativa, em termos de uniformidade e variedade, e de especialidade.

5 Ver Perez Moreno - ob. cit. - p. 11.

cit. Perez Moreno - La Evolución de las formas de empresa - ob. it. pág. 19 e segs. 
Realisticamente, o princípio não é outro que este: reconhecer-se no significado histórico e atual a posição da Administração na sua manifesta tendência para outorgar poderes ou delegar funções, no atendimento de uma verdade que procura através de entes menores integrar o poder administrativo, na sua ação direta ou indireta. ${ }^{7}$

Subjetivamente, no caso das empresas e das fundações, está acontecendo isto: um fenômeno-processo em virtude do qual está o Estado transferindo competência variada a órgãos autônomos com uma diminuição de subordinação que se encontra justificada diante dos efeitos periféricos de natureza econômica e social.

Nunca, porém, relegando os pressupostos de coordenação administrativa indispensáveis para atingir a realização prática peculiar à organização estatal e de unidade na atuação de todos os órgãos públicos, pois submetida continua a Administração ao princípio básico de instrumentar-se em técnicas que sirvam à unidade de fins.

\section{§ 7 ? - ADMINISTRAÇÃO INSTITUCIONAL}

Com justa razão, ENTRENA CUESTA, ao estudar a competência administrativa, não esquece o que chama de relaçóes interorgânicas. São relações de tal natureza que, não só consubstanciam princípios de coordenação, mas também conjunto de funções cuja titularidade se atribui por força de ordenamento jurídico. ${ }^{8}$

Convém, outro tanto, lembrar, não esquecendo as formas de controle exercidas pelo Estado, que as prerrogativas da Administração se estendem em planos que implicam em obrigaçōes: prerrogativas que não se conflitam com as garantias privadas e nem confundem regime administrativo com procedimento jurídico-legal.

7 Consultar: Garcia Trevijano - PRINCIPIOS JURIDICOS DE LA ORGANIZACIÓN ADMINISTRATIVA - Madrid, 1957; Santi Romano - DECENTRAMENTO ADMINISTRATIVO - Scritti minori - II - Milano, 1950; Martinez Useros - LA ORGANIZACIÓN Y SUS PRINCIPIOS INSTITUCIONALES - Murcia, 1960; Valina Velardo - TRANSFERENCIA DE FUNCIONES ADMINISTRATIVAS - Madrid. 1964; Eisenmann - CENTRALIZACIÓN ET DECENTRALIZATIÓN - Madrid. 1964; Eisenmann - CENTRA 1948; e Franchini - LA DELEGACZIÓN E AMMI-
NISTRATIVA - Milano, 1950.

8 Rafael Entrena Cuesta - CURSO DE DERECHO ADMINISTRATIVO - La Competencia Administrativa y las Relaciones Interorganicas - Capl-
tulo $\vee$ - pág. 175 e segs. 
É de compreender o conteúdo tridimensional do Direito Administrativo moderno, quando

a) numa determinada esfera as suas normas regulam a organização administrativa;

b) numa determinada área estabelece relações interorgânicas entre os entes públicos;

c) num determinado limite relacional jurisdiciona entes públicos e particulares conjugando prerrogativas e garantias. ${ }^{9}$

Bem informa ENTRENA CUESTA, esclarecendo com precisão doutrinária, que a administração institucional se constitui quando integra na Administração todos os entes públicos menores de caráter não territorial, isto é, aqueles entes que se apresentam em forma derivada e com personalidade jurídica definida legalmente. ${ }^{10}$

Para o catedrático de Barcelona, ao que entendemos, incluem-se entre os entes institucionais, ou de administração institucional, as denominadas empresas públicas pelo que dispõem de prerrogativas próprias à Administração e as fundações pelo seu caráter de estrutura e de funcionamento administrativo. ${ }^{11}$

Com as fundações, para exemplo, o que importa, está na personificação de um fim ou de uma função, pouco importando a técnica seguida para criá-las ou seja a técnica fundacional, de vez que elas dependem da vontade legal criadora, do princípio normativo admitido em lei ou do que o Estado pretende pelo ato instituidor.

Não devemos, portanto, levantar dúvidas, onde dúvidas não existem. Pelas determinantes da criação legal, pelo caráter institucional e regime jurídico, as fundações como as empresas públicas inscrevem-se como organismos autônomos ou como entes menores de natureza administrativa, sob a tutela do Estado.

Tudo reside no motivo determinante da criação que tende para o cumprimento de um fim de serviço público: quanto ao caráter institucional nas empresas públicas e fundações afirma-se não só pelo cumprimento das finalidades específicas, mas pelo desejo do Estado em descongestionar a Administração central.

9 Rafael Entrena Cuesta - ob. cit. - p. 61.

10 Entrena Cuesta - La Administración Institucional - ob. cit. Pág. 337 e segs.

11 Entrena Cuesta - ob. cit., págs. 338/9. 


\section{§ 80 - AS FUNDAÇס̋ES}

Considere-se que, depois das autarquias, passada a febre das sociedades mistas, apareceram as fundações na área da Administração e do Direito Administrativo, como o fato mais notável de descentralização ou desconcentração, como a iniciativa legal mais apropriada ao atendimento de certas obrigações estatais e públicas.

Correspondendo às fundações, as empresas públicas se impuseram na esfera administrativa estatal, num mesmo plano igual de atividade indireta, atuando ou não num regime de monopólio, gestionando ou não um serviço público em sentido estrito, como resultado de processo racionalizante e nacionalizador. 12

Separados os fins, discriminada a finalidade, adotado 0 processo privado de personificação jurídica, a posição das fundações como das empresas públicas no quadro da Administração institucional é a mesma, irrelevantes que se tornam as formas e os tipos casuísticos, ou as correlações com a organização administrativa.

$\mathrm{Na}$ recente evolução planejada diante das exigências do desenvolvimento econômico e social, verifica-se pelo sentido e alcance do fim público, que a realidade do ordenamento jurídico, apaziguou tendências diversas em favor de condições cuja tipicidade não obrigam o Direito Administrativo a qualquer opção.

A significação antológica da forma jurídica adotada para as fundações e empresas não implica com a doutrina clássica, pois a perspectiva o que visa outra coisa não é que a valorização do sistema jurídico privado na gestão de setores públicos representativos de problemas que afetam a competência do Estado.

Alguns pontos são comuns, nas empresas públicas, à atividade concreta das fundações. PEREZ MORENO enumera três que aceitamos:

a) insuficiência da iniciativa privada, incapaz de corresponder a fins de caráter geral para as diversas modalidades fundacionais e empresariais;

b) a conveniência de se impedir ou combater as práticas restritivas ao exercício da competência estatal;

12 Garrido Falla - apud Perez Moreno - ob. cit., pág. 33. 
c) imperativos de defesa dos altos interesses nacionais no tocante à exploração de novas e velhas fontes econômicas. ${ }^{13}$

No que respeita às fundações, com o critério de competência técnica reforçando o critério da competência jurídica, a intervenção estatal pelo ato de criação traz no seu bojo como conseqüência do processo privado a figuração de um órgão ou organismo-ente coordenado aos órgãos centrais de governo e de administração.

No exercício de uma função, de gestão de serviço público, vigora o princípio da discricionaridade organizacional dentro da ordem jurídica, segundo o qual o Estado pela Administração no uso da sua autoridade legal pode outorgar-se o papel de interventor para assistir interesses sociais, assistenciais ou educacionais.

Mudada a equação, quanto ao fim, da atividade-forma-jurídica, as fundações passam a assemelhar-se às empresas públicas, preponderando sempre a autonomização indispensável à personalização do ente administrativo, e tendo no substrato personificado as exigências que revestem a pessoa jurídica na sua extensão legal.

Com as fundações, o fenômeno que acontece é este: a Administração criando-as, personifica entes, como necessidade de obedecer o princípio da divisão do trabalho administrativo para a realização de fins que justificam os meios, sem com isso violentar a ordem jurídica ou desmerecer as tarefas que lhe devem ser cometidas.

Nada há demais que a Administração recorra à personificação jurídica e privada através dos instrumentos de direito privado, eis que as formas sempre novas que possa adotar integram-se à organização geral do Estado acudindo situações e tarefas que a rigor vinculam-se a setores diretamente afetados pelo interesse coletivo.

Pelo princípio da divisão do trabalho administrativo, que permite ao Estado ampliar as suas áreas de ação administrativa, jamais será aconselhável a concentração de tarefas públicas de fins de serviço público, quando a Administração pode impor normalmente o recurso da necessária e peculiar personalidade jurídica.

§ 9? - DETERMINAÇÃO DO CRITÉRIO INSTITUCIONAL

A Administração pública, respeitando a organização politica estatal, em sentido amplo e de sistema orgânico, está $51 / 2$. Ver LA FORMA JURIDICA DAS EMPRESAS PÚBLICAS - págs. 
naturalmente integrada por uma pluralidade de entes políticos públicos: o Estado, pelo óbvio, em primeiro lugar, e, em segundo lugar, a série de entes que fazem a denominada Administração indireta, entes esses que possuem caráter territorial e outras vezes caráter institucional. ${ }^{14}$

As funções públicas que se distribuem entre os entes administrativos conforme critérios de ordem e de eficácia, de meio e de fim, de necessidade e de serviço, cada uma dessas unidades constituindo um organismo peculiar, ou um órgão administrativo, dão como resultado a organização geral administrativa, não só pelo conjunto de relações jurídicas recíprocas, mas pela hierarquia, coordenação e subordinação.

Acompanhando o pensamento de ENTRENA CUESTA, estamos concordes que o órgão com elementos pessoais e materiais adstritos à realização de um fim, forma uma instituição: essa característica institucional de órgãos administrativos, conforme a atribuição de personalidade legal, face às relações que só podem existir entre sujeitos de direito, explica-se pela conduta da Administração quanto às obrigações estatais. ${ }^{15}$

Apreende-se, portanto, que é neste plano que se colocam as fundações e as empresas públicas, estimando-se:

a) o limite da competência administrativa;

b) a titularidade para a função específica;

c) a esfera própria de atuação legal e jurídica;

d) a categoria dos direitos recebidos;

e) o caráter dos deveres assumidos;

f) a consecução do interesse público.

Em conseqüência dessa postura, da existência da pluralidade de entes administrativos integrando a Administração, do princípio que leva o Estado à categorizar pessoas jurídicas, é certo que as fundações como as empresas públicas ostentam além de competência subjetiva também competência orgânica.

Uma e outra competência, a orgânica e a subjetiva, estão nas funções legitimamente exercitadas: há, por assim dizer, um direito subjetivo ao exercício dessas funções; há, por condição do ordenamento jurídico, órgãos com atributos de capacidade preferencial no sentido de que são titulares de direitos e de obrigações.

14 Rafael Entrena Cuesta - Caracteres y Contenido de la Administración Institucional - ob. cit., pág. 338 e segs. segs.

15 Ver CURSO DE DERECHO ADMINISTRATIVO - cit., pág. $346 e$ 
Considerando a importância da competência administrativa na organização e atividade dos entes públicos ou criados pelo poder público, ressalte-se que as regras adotadas seguem uma determinação de critério institucional:

a) quando implicam com a adoção de formas específicas, isto é, indicativas do modo de como possam ser exercitadas;

b) quando a especificação constitui-se em atributo do órgão, isto é, resulta de princípios concretos reguladores do pretendido serviço público.

Destaque-se, outrossim, a influência da coordenação administrativa nas diferentes técnicas de atuação estatal, que não escapa:

a) da hierarquização como estrutura;

b) da fiscalização e da tutela legal;

c) da subordinação que reduz à unidade a multiplicidade dos entes administrativos.

Através de relações de subordinação, porque não dizer de supremacia, pela hierarquização passam a dispor os órgãos superiores de faculdade de controle de conduta dos órgãos inferiores, mediante uma ordenação sistematizada que encontra guarida na ordem jurídica e nos princípios positivos de natureza legal.

Nas fundações, como nas empresas públicas, dirigir, inspecionar, ordenar e tutelar, é condição imperativa da organização administrativa: jamais a fiscalização pela tutela, na repartição do trabalho administrativo, infringe a autonomia da pessoa jurídica ou restringe a delegação concedida para a eficácia do serviço público.

\section{$\$ 10^{\circ}$ - O CONTROLE OU TUTELA}

Está claro, que o controle, ou a tutela, não se presume, porque está expressamente consagrado no direito positivo. E, como supõe, uma exceção à autonomia do ente descentralizado, deve Ser aceito restritivamente para consagrar a Administração na unidade da sua capacidade geral de autodeterminação.

Assim é com as autarquias. Com as fundações e as empreSas públicas, num sentido de limitação em função de atividade Permitida. A causa da tutela administrativa reside na necessidade de não se quebrar a unidade na atuação de quantos entes Persigam os fins públicos, fins que são inerentes à atividade estatal. 16

R. E. Cuesta - ob. cit. — pág. 153. 
Para RAFAEL ENTRENA CUESTA, entre a hierarquia e a polícia administrativa, está o conteúdo da tutela administrativa integrada pelas faculdades de controle outorgadas com caráter limitado pelo direito positivo ao ente cujo fim e o serviço público, não se admitindo, porém, livremente, que o sujeito tutelante possa ditar ordens ao sujeito tutelado. ${ }^{17}$

Prevalece, como no caso das fundações, o princípio criador que se transforma em orientação estatutária. Ou no caso das empresas, onde a tutela visa lograr à falada unidade de atuação, sem o que impossível seria estabelecer-se a legalidade e a oportunidade de atos passíveis de controle jurisdicional.

Afirmando-se, como pondera PEREZ MORENO, que a Administração personifica "organizaciones" como forma articuladora do princípio de divisão do trabalho, ou que a concentração das tarefas assumidas pela Administração impõem necessidade de distribuição, nada mais normal que a exigência do controle ou da tutela administrativa. ${ }^{18}$

$\mathrm{Na}$ Administração indireta, o papel atual das fundações, como o papel que representam as empresas públicas, ambas levadas à formação através do recurso da personalidade jurídica e privada, corresponde pelas prerrogativas outorgadas a um mesmo objetivo prático: servirem o Estado como compartimentos da Administração geral, de atuarem em nome do Estado em áreas públicas diretamente afetadas.

$\mathrm{Na}$ expressão do professor Sevelha,

- "la personificación de esos entes constituye, en definitiva, la creación de nuevas formas jurídicas, de nuevos sujetos para los que se elabora un Derecho especial". ${ }^{19}$

Mas de novas formas jurídicas, com a adoção de uma forma jurídica de direito privado, por onde não pretende a Administração fugir da aplicação do Direito geral normativo desde quando para os esquemas clássicos de serviço público, submete fundações e empresas ao direito privado para gestionar fins
públicos.

Estamos com GARRIDO FALLA quando define a descentralização no seu rigoroso sentido dinâmico com a transferência de funções ou competências dos órgãos estatais às demais pessoas jurídicas públicas, mas não só transferência às pessoas

Idem - ob. cit. pág. 152.

18 Ver LA FORMA JURIDICA... - cit. - pág. 71.

19 Perez Moreno - ob. cit. - pág. 74. 
públicas como às privadas de sua criação mediante controle ou tutela. ${ }^{20}$

A mesma indagação que vale para as empresas públicas é válida para as fundações: estão elas, fundações e empresas, enquadradas à organização estatal? A resposta só pode ser afirmativa, pois não há polêmica lógica quando entes descentralizados ficam submetidos à tutela administrativa por formação coativa.

Concordar, não obstante, com GARRIDO FALLA, para afirmar que as empresas públicas não estão enquadradas na administração estatal, mas que fazem parte da administração pública, não é o caminho mais adequado para a solução do proble$\mathrm{ma}$ em relação ao que o Estado pretende realizar por meio de Pessoas privadas. ${ }^{21}$

Em falando de descentralização funcional, observando-se a Administração no seu aspecto intervencionista, ou apontando como realidade o fenômeno da integração orgânica do Estado, não há como poder distingui-la da descentralização por servifos, tal a semelhança de propósitos em face da relação juridica.

Basta aqui, o controle ou a tutela, para aclarar-se a natureza da relação entre fundações e empresas como entes descentralizados e a Administração: qualificar essa relação não é trabalho da doutrina e nem da crítica doutrinária, mas do direito por motivo de normas gerais e por conseqüência estatutárias.

\section{$\S 110^{\circ}-$ A FUNDAÇÃO-EMPRESA}

A tese aceitável, que ainda está no domínio da doutrina, Pertence, no momento, a URBANO VALERO AGUNDEZ, com a Supervisão de JOSÉ GIRON TENA, ambos da Universidade de Valladolid, na Espanha. ${ }^{22}$

É plausivel a existência da fundação-empresa? Pode a sível ção surgir como uma nova forma de empresa? Será posivel uma empresa ter caráter fundacional? Em razão da estru${ }^{20}$ Ver ADMINISTRACIÓN INDIRECTA DEL ESTADO Y DESCENTRALI-
ZACIÓN FUNCIONAL - Madrid, 1940; Valina Velardo - TRANSFERENCIA FUNCIONES ADMINISTRATIVAS - Madrid, 1964.

TIVA $^{21}$ - Fernando Garrido Falla - LA DESCENTRALIZACIÓN ADMINISTRA1969 . Ver LA FUNDACIÓN COMO FORMA DE EMPRESA - Valladolid, 
tura e do regime jurídico poder-se-á conjugar numa mesma pessoa duas manifestações jurídicas diferenciadas? No interesse público permite-se ao Estado adotar regime comum contrariando disposições de procedimento legal?

Como pode a fundação ser utilizada como empresa? Mesmo havendo conexas, como harmonizar a idéia de fundação com a idéia de empresa? Já não existem fundações que agem com fins de empresa? A organização de uma fundação como empresa pública deve admitir configuração própria fora do princípio estatutário? E a empresa pública sob forma fundacional conflita-se com a natureza das instituições?

As indagações, no que não escapam do pensamento jurídico realista, merecem inteira concordância frente à realidade do Estado moderno como organização política e administrativa. Não se concebe, hoje em dia, o poder público não interessado pelas novas técnicas de atuação no campo do direito, quer público ou quer privado. O que importa é que o serviço público seja prestado na extensão das necessidades coletivas.

Se o veículo da prestação forem as fundações, nada mais justo que adotá-las na dimensão de uma racional descentralização funcional. Caso o veículo aconselhável sejam as empresas, certo que se faça delas expressão dos serviços econômicos que o Estado tem por obrigação prestar. Havendo, no entanto, conveniência de uma forma conexa que o processo novo ganhe estrutura no contexto do regime administrativo.

Ao Estado, pela Administração, que não se permite o alheamento quanto à possibilidade apresentada de acolher novas fórmulas indicadas pela prática e que melhor forem condizentes com a execução dos serviços públicos. Para a problemática estatal importantes serão sempre os instrumentais administrativos que possam adequar os problemas às soluções, os métodos às resultantes de fins necessariamente públicos.

Ademais, mesmo que não haja orientação predominante razão alguma se pode opor à possibilidade de constituição de fundações-empresas. A organização de uma fundação com forma de empresa e conteúdo empresarial e a inclusão dela como organismo da Administração pública, em coisa alguma poderá alterar a influência do Estado quando no exercício pleno das suas prerrogativas primaciais e de supremacia.

Substancialmente não se modifica, nem pelo processo jurídico, a natureza da instituição. A atividade executiva que se torna estatal nas empresas e fundações, resulta de funções an- 
teriormente outorgadas por ato de autoridade competente encarregada na ordem jurídica de promover satisfações coletivas, econômicas e sociais. Quanto à instituição, mantém-se na pureza da sua forma, apesar da evolução dos fatos públicos.

\section{$\S 12^{\circ}$ - A SITUAÇÃO NO DIREITO POSITIVO}

$\mathrm{Na}$ verdade dissemelhanças essencais não existem em questão formal entre as fundações criadas pelo Estado e as empresas públicas estatais. São simplesmente pessoas administrativas funcionalmente descentralizadas na órbita da Administração institucional. Aparecem e se criam, na ordem jurídica administrativa, em atendimento de um serviço que é público, do Estado, e, portanto, do interesse da Administração.

No direito positivo a situação sequer se altera em relação à orientação tomada pelo Direito Administrativo. Jamais houve segredo, nem conflito doutrinário, com respeito à posição das autarquias. Oposição não houve, entre os doutrinadores, quanto à participação das entidades autárquicas no quadro da Administração geral. Sobretudo, as leis civis e os Códigos, sentiramse respeitadas e estimuladas. ${ }^{23}$

No entanto, antes de formalizadas legalmente, as autarquias inexistiam para o direito positivo. Como pessoas jurídicas, ouvidos os códigos de leis civis, não tinham lugar próprio na tradicional classificação de pessoas. Bastou a manifestação da vontade estatal para que as autarquias viessem a ocupar posição de destaque na Administração, atendidas de plano que foram certas áreas de interesse público.

Irrelevante, portanto, a controvérsia, no que diz com as empresas públicas e as fundações. Pelas possibilidades institucionais, a Administração insuficientemente aparelhada, não está impedida de amparar-se nos institutos privados. Ao contrário, têm neles elementos jurídicos com que cumprir obrigações inalienáveis, desde que mantenha o Estado a sua tônica de poder político com responsabilidades administrativas.

Não prevalecem com as fundações as dúvidas que incidiram sobre a conceituação e a posição das autarquias. Possuem

Como No Brasil já vai longo o processo de consagração das autarquias importantes autores jurídicas públicas integradas na Administração estatal. Três Fonsecantes autores fazem história na literatura brasileira: Tito Prates da tônio Ban - AUTARQUIAS ADMINISTRATIVAS - S. Paulo, 1935; Celso An-

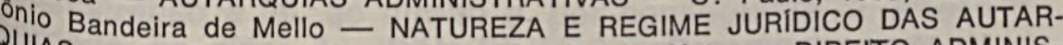

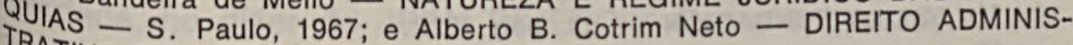
TRATIVO DA AUTARQUIA - RIo, 1960. 
os entes fundacionais características jurídicas marcadamente acentuadas no direito positivo. Bastam-se pelos elementos integrativos que não isolam o Estado da tutela legal. Elementos que são componentes e de conteúdo jurídico, seja qual seja o fim da promoção fundacional.

De maneira igual, com as empresas públicas, adotou a $\mathrm{Ad-}$ ministração o comportamento aconselhado pelo direito positivo. Recorre às empresas, respeitando a ordem jurídica, objetivando indiretamente determinada prestação de serviços. Sem, contudo, precisar violentar regras de procedimento aconselháveis à adequação do problema. Com isso, não excepcionaliza, mas integra buscando a colaboração do direito privado.

Está bastante clara a afirmação esclarecedora de URBANO VALERO AGUNDEZ:

- "en la actual situación de nuestro Derecho positivo, a falta de una reglamentación legal de la fundación como forma de empresa, todas las reservas seriam en ella reservas estatutarias o reservas facultativas". ${ }^{4}$

$\mathrm{Na}$ vontade instituidora ou criadora não intervém o direito positivo e nem as regras recomendadas de procedimento legal. Cabe ao fundador, ou criador, no caso o Estado, estabelecer as motivações do ato, procurando as formas mais suscetiveis de entrosamento de fim público à Administração. Na declaração da vontade afigura-se com precisão a harmonia entre a norma privada e $O$ interesse público.

\section{Para URBANO AGUNDEZ,}

- "no parece haber motivo alguno para dudar de ello, toda vez que al fundador le corresponde estabelecer la medida en que los benefícios fundacionales, también en el caso da fundación-empresa, deben ser distribuidos entre sus destinatarios o aplicados en general, a los fines fundacionales"'. ${ }^{25}$

Conclui-se, portanto, que nem do ponto de vista econômi$\mathrm{co}$, nem do ponto de vista jurídico, hajam obstáculos à criação da fundação-empresa. As reservas aconselháveis seriam estatutárias quanto aos meios e com relação aos fins. O exame da conveniência fica na alçada administrativa. $O$ problema da possibilidade pertence à Administração quando no exercício das suas faculdades discricionárias.

25 Urbano Valero Agundez - ob. cit., pág. 322. 


\section{$\S 13^{\circ}$ - ADMINISTRAÇĀO E ORGANISMOS AUTOONOMOS}

Já o Direito Administrativo esgotou uma farta literatura de como na prática institucional e organizacional comportam-se os organismos autônomos. Surgem eles pela necessidade de várias imposições: as políticas, as sociais, as assistenciais, as econômicas, descentralizando ou desconcentrando as funções estatais.

Não existem, porém, no direito comparado, e nem nos direitos nacionais, princípios gerais reguladores da estrutura administrativa dos organismos autônomos. Princípios que passam a obrigatórios para a formação de entidades cuja finalidade correspondam a serviços públicos ou de interesse público.

Preferivel a expressão prerrogativas da Administração para com ela dar sentido às iniciativas que se tomam em todas as dimensões da atividade estatal: na verdade são prerrogativas de quem inclusive tutela o direito na sua aplicação material e responde pelos problemas de uma sociedade política em deSenvolvimento.

Apesar da descentralização, os organismos autônomos são entidades afluentes em face da Administração. Para os países desenvolvidos, a meta outra não será que aquela favorável à desconcentração do trabalho administrativo, num Estado de direito que possibilite ampla distribuição de funções e atribuições especificas.

Nos países em desenvolvimento, a importância das novas técnicas distribuidas de procedimento é ainda maior, considerando-se que o Estado não é apenas uma organização de polícia ○ de negócios fiscais. Como corpo político de uma nação, o Estado é um complexo orgânico, sofrendo transformações históricas de regime e de sistema.

Deve, por isso, como unidade e pelos seus órgãos, de íngeneidade de funções que caracterizam a Administração, camidole legislativa, jurisdicional e executiva, em razão da heteroliticar dando formas às diversas manifestações da sociedade pociment sem o que não poderá atender o que exigem os acontecimentos sociais.

Admão se trata, hoje em dia, de submeter, obviamente, a liberdistração à lei, ao direito e, por conseguinte, à defesa da $>$ 
perior, complexa e composta, o Estado, está orientado por distintos ordenamentos jurídicos que não fogem às transformações do tempo histórico.

Nos organismos autônomos encontra o Estado os meios jurídicos de expansão que correspondem à universalidade da problemática administrativa, cumprindo-se assim mediante postulados de direito comum e público, de vez que o Direito Administrativo tornou-se fruto de duas revoluções do século XIX: a política e a técnica. ${ }^{27}$

Vigora destarte, na aplicabilidade e na prática, o princípio da hierarquia normativa, sobretudo organizacional, escalonando a atuação pública estatal em termos de realidade geográfica $e$ institucional, unificando na variedade e planificando nas mais distintas relações de autonomia e subordinação.

Em concordância, pois, com o ordenamento jurídico, os organismos se integram na Administração nos limites da competência concedida. Seja a competência de atribuição genérica quanto ao fim ou específica, personaliza e titula pela vontade estatal serviços administrativos institucionalizados.

\section{$\S 140^{\circ}-$ A MODALIDADE FUNDAÇÃO NA EMPRESA}

$A$ fisionomia de qualquer figura jurídica, principalmente as nascidas do direito positivo, define-se pela expressão técnica ou por um complexo de elementos técnicos que possibilitam atuação no ordenamento jurídico estabelecido. O fim fundacional, sendo o interesse público, não impede objetivo de natureza econômica.

A função do fim fundacional no regime jurídico das fundações, não obstante a estrutura ou o funcionamento delas, não se conflita com a idéia de empresa, desde que o patrimônio esteja destinado à efetivação de resultantes econômicas e diretamente comprometido com o que pretendeu o fundador no ato de instituição.

Está visto que o conceito atual de fundação não se confunde com o conceito tradicional, superadas que estão aquelas finalidades clássicas em virtude da expansão do interesse público em áreas anteriormente entregues à responsabilidade $d a$ iniciativa particular, onde o Estado apenas fiscalizava e năo
tutelava.

27 Jean Rivero - COURS DE DROIT ADMINISTRATIF COMPARE pág. 27 e segs. 
Atualmente, e os exemplos são tipicamente fundacionais, as fundações não se classificam tão-somente como culturais, caritativas, beneficentes ou religiosas. Vão muito mais além com a intervenção direta do poder público quando o Estado procura atender certos setores criando como fundador entes que prestam serviços públicos.

Nada há demais no fenômeno. Facilmente é explicável diante de certos problemas que exigem solução jurídica adequada. É para o poder público uma questão de necessidade promover a criação de organismos supletivos encarregados de uma finalidade e com bens e direitos que se incorporam ao patrimônio fundacional.

O relacionamento, portanto, diz respeito ao fim, à finalidade, ao que pretende o Estado quando se faz fundador de uma fundação. Em principio, qualquer classe de bens pode constituir o elemento patrimonial de uma fundação, sem com isso perder o Estado em substância aquilo que pretende como fim público ou administrativo.

Em qualquer caso onde haja a interferência criadora do poder público, a afetação dos bens a um fim predestinado, reSulta de uma obrigação relacional, de um direito real ou de uma vontade protegida pelo direito, vontade essa vinculada ao ato instituidor da pessoa jurídica, seja a pessoa uma fundação ou uma empresa pública

Simplistamente analisando, tendo em conta a concreta manifestação da vontade estatal, identifica-se o fim institucional tanto nas fundações como nas empresas, em razão do processo que se aplica ao fato, em virtude da afetação de bens que motivaram a criação de um novo sujeito jurídico e personalizado.

É lógico que, se com a forma jurídica de empresa se pretende criar um sujeito de atuação econômica, dotado de uma Organização jurídica especial para o cumprimento da dita atividade, nada impede que a pessoa seja uma fundação com Personalidade peculiar e característica orientada para fins emPresariais.

Para VALERO AGUNDEZ, a fundação-empresa é uma Uundação: uma fundação com base na titularidade jurídica imediata sobre a empresa, em virtude de uma exigência institucional derivada da força normativa dos estatutos, da vontade do fundador e da caracteristica atividade econômica que traz como fim. ${ }^{28}$

28 Ver LA FUNDACIÓN - Diversas Manifestaciones de la Fundación ob. cit., pág. 129. 


\section{§ $15^{\circ}$ - A QUESTÃO DA PERSONALIDADE JURIDICA}

Por paradoxal que seja, a questão da personalidade jurídica já não é mais uma questão de alta indagação: no comum das vezes, o procedimento estatal é típico do direito público, orientando-se por princípios não de opção estatal quanto ao regime, mas de potestade pública que dá à Administração capacidade para soluções buscadas no direito privado.

Qual o regime juridico das fundações, no Brasil e no Direito comparado? Qual o regime jurídico das empresas públicas no Direito Administrativo, brasileiro e comparado? Ao que parece não existem distinções que possam preocupar a posição do pensamento doutrinário.

A intervenção do Estado na ordem econômica e social é o traço de união na sistemática entre as fundações e as empresas. Levada a desempenhar atividades indiretas de natureza diversificada, a Administração adotando personalidade jurídica de direito privado apenas tende para conveniências de política administrativa em face da organização estatal ? ${ }^{29}$

Cabe ao Estado, na individualização, ou personificação de serviços essenciais, decidir quanto à forma e ao conteúdo da outorga ou delegação e na decisão determinar o procedimento e o fim: autarquias, sociedades de economia mista, empresas públicas e fundações serão os veículos mais apropriados para uma efetiva atuação indireta do poder público.

Encontram-se, assim, harmoniosamente, dentro da esfera do Direito Administrativo, a excelência de dois regimes jurídicos: o regime jurídico público e o regime jurídico privado, ambos os regimes marcando prerrogativas e sujeições no melhor proveito do serviço público indireto. ${ }^{30}$

O regime jurídico privado das empresas públicas, como a personalização jurídica das fundações, decorrem da própria natureza das pessoas privadas que são: a presença do Estado, pela Administração, no caso das empresas, objetiva fins públi-

29 No Direito positivo brasileiro ambas as entidades estão definidas no Dec.-lei n? 200, e no Dec.-lei n? 900. Explorar atividades econômicas e outras atividades configurando pessoas jurídicas que a lei prevê, não é mais mistério algum para a doutrina em razão da lei. Adotar o regime juridico está na vontade do Estado. Trata-se aqui de descentralizar para efeito de colaboração. No fundo está o interesse público.

30 Como é óbvio, por exemplo, a empresa, recebe o nome de pública, quando é criada e mantida pelo Estado (Ernest Forsthoff - TRATADO DE DERECHO ADMINISTRATIVO - pág. 662). 
cos, isto é, status legal de onde ressaltam-se caracteres típicos e constitutivos específicos. ${ }^{31}$

Em resumo: quer as empresas públicas, quer as fundações, atendendo a peculiar personalidade jurídica, constituem-se atraVés de patrimônio estatal, personalizado sob a forma de pessoa de direito privado, criadas por lei para gerir interesses públicos afetados a fins econômicos, sociais, assistenciais ou educacionais, sempre um serviço público.

Vale, portanto, o fim de interesse ou de serviço público. Fim que fica submetido a regime jurídico que melhor convier ao Estado dentro da ordem jurídica estabelecida. Fim personalizado juridicamente dentro de esquema privatístico que não desmerece a Administração nas suas prerrogativas públicas e de atuação na ordem pública geral.

\section{$\S 16^{\circ}$ - METODOLOGIA DO DESENVOLVIMENTO}

Tornou-se convincente que o mais importante para o Estado moderno é o processo e não a forma jurídica somente: as técnicas administrativas podem e devem variar sem violentação da ordem jurídica, ficando a Administração com a responsabilidade de encontrar a melhor solução para os seus Problemas específicos.

Uma organização ou uma entidade descentralizada é muito mais do que uma simples pessoa jurídica: precisam os entes da Administração indireta atender as necessidades humanas em harmonia com as metas administrativas, num comportamento afeito às instituições que evoluem em razão da dinâmica social que impõe mudanças de estrutura.

De bom programa administrativo não pode ser cristalizado, porque deve ser orientado segundo as necessidades específiCas imediatas do Estado. Qualquer estrutura rígida acabará totalmente inadequada às manifestações coletivas estatais imPerativas, de vez que a Administração não está alheia aos impulsos resultantes do desenvolvimento social e econômico.

Exatamente para atender às necessidades públicas é que a Administração se torna flexível: aperfeiçoar, portanto, os métodos, tornando-os capazes de atender o desenvolvimento, ou31 Ver Nicola Balog - A ORGANIZAÇÃO ADMINISTRATIVA DAS EM-
PRESAS PÚBLICAS - RDA - 88/41; Jean Rivero-DROIT ADMINISTRA-
TIF IT - págs. 424/5; Natalia Gail - AS EMPRESAS ESTATAIS NA FRANÇA, 1TÁLIA E POLÔNIA - RDA - 70/43; Ernest Forsthoff - ob. cit. - pág. 62. 
tra coisa não é que colocar o Estado à altura dos problemas que exigem aparelhamento administrativo próprio.

Já num Anteprojeto de Lei Orgânica do Sistema Administrativo Federal brasileiro, com respeito aos serviços estatais dependentes da Administração direta, antecipava-se com inteligência no parágrafo 19 do seu art. 7?

- "equiparam-se à empresa pública, para os efeitos desta lei, as fundações instituidas com recursos exclusivos da União, quaisquer que sejam as suas finalidades". ${ }^{32}$

Não há como não saber que as atividades econômicas diferem intrinsecamente com complexidade. Quanto à eficácia da Administração depende, em grande parte, das leis e instituições que se integram no quadro do regime jurídico, e que determinam a existência de pessoas e de entidades administrativas $\mathrm{Ca}^{-}$ pazes pelos novos métodos de dar sentido ao desenvolvimento.

Equiparar, portanto, as empresas públicas às fundações, objetivando a dinâmica do desenvolvimento administrativo, chama-se ajustar conhecimentos técnicos às imposições do processo tecnológico, ampliando, assim, a capacidade estatal, em termos de governo integrado na reformulação de processos que desconcentrem pela divisão o trabalho da Administração.

Não resta dúvida que em administração os objetivos, "a política de ação e os procedimentos são sempre relacionados de modo dinâmico e tendem a se tornar focalizados no momento de ação e decisão administrativas: desde que as entidades são um todo e suas partes inter-relacionadas, a administração tem de ser encarada como um processo global". ${ }^{33}$ TANO:

Dois corolários são exatos na lição de MARCELLO CAE-

10 - A personalidade é um produto do ordenamento jurídico, concessão exclusiva do Estado. Nunca os homens, com os seus contratos e as suas organizações voluntárias, poderão fazer nascer uma pessoa coletiva, sendo sempre necessária a intervenção do Estado, através dos seus órgãos e autoridades. O reconhecimento é o fator constitutivo da personalidade jurídica.

$22^{\circ}$ - Sendo a atribuição da personalidade apenas a concessão de capacidade jurídica, pode esta ser mais ou menos

32 Homero Senna e Clóvis Zobaran Monteiro - FUNDAÇÕES... pág. 73 .

33 Harleigh B. Trocker - NOVAS PERSPECTIVAS DE ADMINISTRAÇÃO - pág. 35. 
ampla, limitar-se ao direito privado ou estender-se também à esfera do direito público. Mais: quem determina tal capacidade é sempre a ordem jurídica, árbitro de conferi-la em geral ou sob forma limitada, fragmentária ou parcial. ${ }^{34}$

\section{$\S 17^{\circ}$ - SUBSTRATO CERTO NA ORDEM JURIDICA}

Ninguém mais contesta o Estado na sua plena capacidade interventora ou de intervenção no domínio econômico e social. A Administração deve ficar com liberdade para decidir. Nas fundações e nas empresas, ou mesmo na fundação-empresa, depende o patrimônio afetado de quem reconhece a pessoa jurídica e das regras comuns recomendadas pela experiência.

Não se trata, em razão do poder discricionário, de saber ou discutir qual a solução preferível. O reconhecimento específico é taxativo e normativo desde quando a lei confere ao ato instituidor o efeito formal da outorga da personalidade. $\mathrm{O}$ ato de instituição é, pois, assim, a manifestação unilateral da vontade estatal em face do interesse público.

E pacífico que o ato de instituição tem caráter próprio e específico, constituindo uma categoria jurídica peculiar de negócio jurídico unilateral. Na verdade, não há dificuldade algu$\mathrm{ma}$, em conceber-se o Estado na sua qualidade de poder público provendo uma necessidade pública, mas com o ânimo de Cumprir obrigações que lhe são essenciais e imperativas.

Nada mais simples do que aceitar a personalidade como uma qualidade jurídica com substrato certo na ordem jurídica: não há, portanto, restrição, no sentido de que as fundações, como as empresas públicas, procurem fins lucrativos, impostos à sua atividade no ato de instituição.

No entendimento moderno, sem qualquer base material de sustentação econômica, irrealizáveis são as fundações e as empresas públicas. É assim que, entre nós, o Estado tem criado Várias fundações e empresas doando-lhes bens com destinação e fins previamente determinados.

Ultrapassada está a idéia de que as fundações só possam ter fins de utilidade particular. Superadas estão as teorias que só admitem fins de utilidade particular para as empresas estatais. Aqui, no caso $\mathrm{em}$ debate, a propriedade coletiva, ou pública, é eminentemente institucional, ou seja, voltada para a realização de certos fins públicos.

53/4. Caetano fundamentado em Ferrara - DAS FUNDAÇÕES - págs. 
O sujeito do direito à propriedade coletiva, ou pública, é o Estado, sob a forma de uma pessoa juridica constituída com fins de interesse público afetos à Administração. Manifesta a vontade do Estado não há como não admiti-la na sua expressão de força na ordem institucional. Vale, portanto, 0 ato de instituição, o significado do ato criador.

Aqui fica bastante claro: a função que o Estado exercita através das fundações e das empresas públicas, escolhendo os meios de procedimento mais adequados, é uma função de intervenção. Intervenção pela qual a Administração se faz presente na extensão das suas prerrogativas e propósitos, ou como prestadora de serviços tanto sociais como econômicos.

$\S 18^{\circ}$ - INTERVENÇÃO E ATIVIDADE ADMINISTRATIVA

Seria o caso de admitir a Administração agindo conforme impõe o princípio da especialidade. Intervindo em relações jurídicas de direito privado, embora mantendo as suas prerrogativas essenciais. Definindo de acordo com a lei a sua própria conduta e dispondo dos meios necessários para impor o respeito dessa conduta e para traçar a conduta alheia naquilo que com ela tenha relação. ${ }^{35}$

CAIO TÁCITO, informando que a tônica dos regimes políticos passou da abstenção para a intervenção, estabelece algumas premissas:

a) as Constituições se enriquecem com novos direitos econômicos e sociais, tão relevantes para o homem comum como os seus direitos individuais e políticos;

b) o centro de gravidade da ordem jurídica se desloca, progressivamente, do individual para o social;

c) a intervenção do Estado no domínio econômico, que é uma constante do Direito Público contemporâneo, se define ora sob forma programática, ora como norma legislativa, ora ainda, como uma atividade administrativa;

d) o Estado é, atualmente, um prestador de serviços tanto sociais como econômicos;

e) a atividade empresarial do Estado pode chegar sob inspirações variadas, ao monopólio estatal;

f) característica, também de intervencionismo, é o planejamento econômico, tanto do setor público como do privado;

35 André Gonçalves Pereira - ERRO E ILEGALIDADE NO ATO ADMINISTRATIVO - págs. $34 / 5$. 
g) a propriedade, a família, o trabalho, a empresa passam a obedecer a novos pressupostos de interesse coletivo;

h) a liberdade e sobrevivência do indivíduo, a proteção contra os riscos sociais, a garantia de propriedade, da atividade profissional, do comércio e da indústria, se colocam a um tempo sob a proteção e a disciplina do Estado, numa escala que vai da ampliação do poder de polícia às formas mais amplas de socialização da economia. ${ }^{36}$

Esse clima reformista do direito moderno, não leva como espera CAIO TÁCITO à instabilidade das instituições jurídicas tradicionais, mas tão-somente à procura de novas leis e códigos melhor adequados à atuação estatal no que diz respeito com o equilibrio indispensável à consecução da segurança social e econômica. ${ }^{37}$

Tanto nas empresas personificadas, como nas fundações com personalidade juridica privada, ambas as pessoas jurídicas com capital público, os matizes não se diferenciam na evolução histórica, nem na sua expressão mais moderna ou de clima reformista, quanto à atividade do fim e de forma no que diz com a Administração indireta. ${ }^{38}$

Convém, porém, ressaltar que não mais existe hoje aquela tendência à nacionalização dos serviços públicos que impressionou o espírito jurídico depois da última guerra na déCada de 1950, provocando de VEDEL uma atitude radical em favor da politização e em oposição à fase liberal já ultrapassada na sua fisionomia histórica. ${ }^{39}$

$\overline{-}$

C.T.C Ver O DESAFIO DO ENSINO DE DIREITO - Carta Mensal - do 37 Caio Tácito - trab. cit. - loc. cit. - pág. 61.

38 Destacam-se, na apreciação do fenômeno jurídico, face à capacidade interventora do Estado, alguns trabalhos de invulgar mérito prático e doutrinário, como: Aurélio Guaita - DERECHO ADMINISTRATIVO ESPECIAL CA Vol. III - Zaragoza, 1967; Alfonso Perez Moreno - LA FORMA JURIDIDA DE LAS EMPRESAS PÚBLICAS - Sevilha, 1969; F. Garrido Falla - LA th SCENTRALIZACIÓN ADMINISTRATIVA - Costa Rica, 1967; Ernest Forsthoff - TRATADO DE DERECHO ADMINISTRATIVO - Madrid, 1959; Garciadrid, 1967; - TRATADO DE DERECHO ADMINISTRATIVO - Vol. II - MaTIÓN DES; A. Buttgenbach - THÉORIE GÉNÉRALE DE MODES DE GESValero Agundez - LA FUNDACIÓN COMO FORMA DE EMPRESA - Valladolid, 1969 .

39 Ver LA TÉCNIQUE DES NATIONALIZATIONS - Paris, 1946. 
VEDEL largou àquele tempo a expressão que se fez famosa de que o Estado expropriou ou estava expropriando do capitalismo ou dos capitalistas não só suas empresas, como senão também suas experiências e suas fórmulas jurídicas com a intervenção e adoção de formas societárias mercantis constituidas de capital público. ${ }^{40}$

Mas o assombro com a expressão famosa não durou muito, pois o fenômeno nacionalizador haveria de dar lugar ao fenômeno do planejamento com a proliferação de entes de gestão econômica e social, capazes pela via da descentralização administrativa, de atender certos propósitos dentro da estrutura organizacional pública.

A evolução do pensamento jurídico se baseou na necessidade do desenvolvimento econômico o que é político, com a aceitação da presença indispensável do Estado na atividade econômica através de um processo racionalizador que ante a variedade de pessoas causuisticamente criadas, obrigou a $\mathrm{Ad}$ ministração a optar por um regime racional e próprio de cunho eminentemente planejado e de caráter institucional.

Quanto à experiência generalizou-se em todos os países ocidentais de maior desenvolvimento, impondo a necessidade de uma reordenação jurídica assentada nos elementos surgidos da técnica planificada aplicada à organização administrativa, adequadamente sujeita essa técnica às condições de forma, conteúdo e regime juridico.

\section{§ $19^{\circ}$ - A SIGNIFICAÇÃO DA FORMA JURÍDICA}

O caráter econômico, técnico ou de processo, estão no presente vinculando muito mais o Direito Administrativo à Ciência da Administração: importa considerar na descentralização como regime, dois fenômenos que exigem dimensionamento ajustado em planos que se equivalem na ordem decrescente hierárquica e funcional.

No primeiro dos fenômenoss está a organização, mediante a qual a realidade estatal se projeta na realidade política de si mesma, isto é, ordenando formalmente a atividade administrativa instrumental nas diferentes esferas de comportamento

40 Georges Vedel - ob. cit. DROIT SOCIAL - pág. 93. 
público, harmonizando o sistema jurídico com o sistema político. ${ }^{41}$

No segundo dos fenômenos estão as estruturas através e mediante das quais a Administração efetiva a sua atividade de gestão, alargando o quanto possivel a sua capacidade funcional, gerando órgãos, pessoas ou entes, que pela definição de competência e de objetivos, respondem à obrigatória ação estatal em diferentes esferas.

Daí porque, órgãos, pessoas ou entes, exigem forma juridica cuja significação está no sentido da coordenação à organização administrativa, ou seja à organização do Estado, forma jurídica que não se articula senão dentro do regime e da ordem jurídica instituída em razão do que oferece o direito vigente nas suas manifestações. ${ }^{42}$

Compreende-se, portanto, o surgimento das fundações e empresas públicas como participantes da ordem jurídica estatal, sob formas clássicas mas adequadas às exigências do serviço público, criadas dentro do âmbito do ius publicum com o objetivo de alcance político e não só patrimonial, instituídas em diferentes niveis e graus com personalidade jurídica, natureza própria e forma jurídica peculiar aos entes autônomos privados.

Ainda aqui, merece lembrança a lição de PEREZ MORENo, que se torna válida desde quando visualiza o problema em termos genéricos, para afirmar:

"a) la Administración tiene un hambre de nuevas formas que solo el Derecho comun ha sabido y podido suministrarlo;

b) junto a la decantada politización del Derecho comun cabia colocar la privatización del Derecho público, no en cuan-

41 Não cabe aqui, necessariamente, o exame do Estado na sua formação política. Numa visão mais ampla, não há como não atender, pelas suas implicações de regime e de ordem política, o Estado como corpo político. Basta dizer que o sistema jurídico é condição da organização estatal ou do Estado politicamente organizado. Sendo ele, o Estado, federal, apresenta-se em caráter de maior complexidade. É, sempre, por essência, composto, como soma de valores políticos que se integram num mesmo único poder, no caso brasileiro, a União Federal. Por sua vez, a União, năo se realiza sem a participação das unidades federadas. Nos Estados unitários já a organiZação política não exige maiores dimensões. Nele, no Estado unitário, não prevalecem pressupostos que imponham a divisão do poder político, e, por conseqüência, a Administração não sofre divisões ou repartições na estrutura.

42 "En todo caso los problemas a resolver serán el Derecho aplicable a estos entes autonomos, como se relacionam con la Adiministración, y el valor de la atribución de personalidad jurídica en las relaciones con terceros". 
to a sua substancia especifica, ya que la Administración, aun cuando actuando bajo régimen privatistico, no pierde jamás su caracter de "publicas potestas", sino en cuanto a la forma juridica a que se sometem las nuevas tarefas administrativas. ${ }^{43}$

Sem dúvida, não há como contrariar a Administração, ou o poder administrativo, ou o Estado, não admitindo a plena compatibilidade entre a organização do ente segundo a estrutura jurídica mais adequada a seus fins, tendo em conta 0 caráter instrumental e de processo que interesse à Administração no uso das suas prerrogativas.

Sabe hoje a doutrina que o chamado regime privatístico não é estranho à Administração quando expressa a sua vontade pública ou política. Nas pessoas jurídicas fundacionais efetivamente o poder público procura a descentralização funcional ou a descentralização por serviços. Nas empresas, ou através delas, o que o Estado procura é dinamizar um objetivo econômico no plano onde possam preponderar elementos jurídicos combinados do regime jurídico e que melhor disciplinem a forma jurídica.

Certamente, a doutrina, por imposição de certas posições doutrinárias, não se mostra unânime quanto à forma das fundações e das empresas públicas. O processo, porém, deve caber ao Estado, dentro do princípio da unidade administrativa. A obrigação do respeito à legalidade não impede a escolha do regime mais adequado. Tendo em mira fatores condicionantes que dão configuração a tipos de pessoas, tanto pode o Estado adotar a forma pública, ou a privada, se esta lhe parecer a mais conveniente.

Acresce, sobretudo, reconhecer que a característica dos entes fundacionais com forma jurídica de empresa pública está na personalidade jurídico-pública, mas com submissão da sua atividade ao direito privado, especialmente quando o Estado no ato criador define o tipo da pessoa na relação jurídica $e$ diante dos objetivos a alcançar. Assim afirma o Estado, como instituidor e organizador, a sua capacidade do Direito Administrativo. Capacidade que não ampara as fundações privadas.

Preponderam três elementos fundamentais no sentido da caracterização da forma jurídica:

a) o elemento vontade fundadora do Estado;

b) o elemento patrimonial para consecução de um fim;

Ver LA FORMA JURIDICA... ob. cit., pág. 76 . 
c) o elemento organização para cumprimento desse fim com a fixação de meios pessoais e materiais necessários.

A modalidade do ente fundacional, com forma de empresa pública, supõe reconhecimento de finalidades que pela atividade pretendem a gestão de serviços públicos econômicos. A forma jurídica, por conseqüência, responde a uma necessidade, ou a necessidades que se manifestam na esfera própria de responsabilidade da Administração. A colaboração de pessoas privadas na gestão administrativa pública tornou-se num fato natural e numa solução normal do nosso tempo, dado o sentido organizador do Direito Administrativo. ${ }^{44}$

\section{$\S 20^{\circ}-$ CONCLUSÃO}

Enquadram-se, teórica e praticamente, as conclusões que espontaneamente aparecem dos fatos que envolvem a condição administrativa, nos seguintes itens cuja importância indicam a capacidade generalizadora do Estado, no tocante aos serviços públicos que envolvem a plena responsabilidade da Administração.

a) somente pela descentralização funcional e de serviços pode a Administração arcar com as exigências de ordem administrativa, social, econômica e assistencial, que fazem fim para - Estado dentro das suas prerrogativas políticas;

b) essa descentralização caracteriza-se no sentido dinâmico pela transferência de funções ou competências da Administração às demais pessoas jurídicas públicas ou privadas e para atender condições territoriais e institucionais;

c) o nexo causal e juridico entre os entes funcionalmente descentralizados e o Estado impõem a tutela face à natureza da relaçâo, dependência hierárquica, a forma personificada e a forma jurídica adotada;

d) a posição do Estado é a mesma quanto às fundações e às empresas públicas, desde o momento em que as enquadra na organização estatal por constituição coativa;

form e) tanto as fundações como as empresas organizadas em forma de serviço público no sentido geral são fenômenos típicos de descentralização administrativa assumindo a personalidade melhor condizente com o fim esperado;

$44 \mathrm{Em}$ parte é essa a orientação de Perez Moreno quando ressalta bordinportância das relações de cooperação sobre as relações de estrita suordinação - ob. cit., pág. 266. 
f) considerando a relação de hierarquia e a relação de tutela o regime jurídico será sempre aquele que o Estado proferir para todos os entes inferiores que participam ou passam a participar da Administração indireta;

g) na realidade nada há que impeça o Estado de criar fundações com forma de emprêsa destacando no ente autônomo personificado o regime conveniente, e isso em razão da natureza da atividade que pretende exercitar;

h) mostra-se a vontade estatal através do substratum personificado que dá vida ao ato de criação em cada caso para tudo quanto disser respeito à forma concreta, à estrutura jurídica peculiar e organizacional administrativa. DEZ:

Adotamos aqui, sem reservas, a tese de VALERO AGUN-

- "el fundador puede establecer en el negocio fundacional las normas, conforme a las cuales deben estructurarse $y$ atuar los órganos de la fundación". 45

Com o fato, as empresas fundacionais privadas em nada se conflitam substancialmente com a natureza histórica da instituição. A ação do Estado, pela vontade, é a mesma. A necessidade de controle também igual na fundação-empresa.

Quanto ao controle no funcionamento da empresa fundacional será o problema apenas estatutário, pois, em principio, resultante da intervenção de órgãos públicos ou da Administração, a função de poder outorgada pelo fundador, limitase às regras ou disposições que garantem o cumprimento da vontade nascida do ato de instituição.

Paralelo às tradicionais formas de empresa a nova forma de fundação, com peculiaridades econômicas no setor privado ou público, dificuldade maior não oferece no tocante ao conceito, possibilidade e regime jurídico. Ressalte-se, fundamentalmente, como essencial, a vontade do fundador, em torno da idéia central, que o levou à criação do ente.

Como nas fundações, pessoas criadas de direito positivo, no fim está precisamente o seu objetivo. A figura típica, histórica, clássica das fundações, já não basta na atualidade. As exigências do interêsse público de tal maneira aumentaram que estão a exigir do Estado ação mais eficiente e disciplinadora. Ação instrumental que se ampare nos elementos coadjuvantes que the oferece o direito privado.

45 Ver LA FUNDACIÓN - ob. cit., pág. 314. 
No sistema do Código Civil, apesar dos preceitos unitários aplicáveis, não se diz ao certo o que seja o interesse ou a necessidade públicas. Em conseqüência, o interesse público, ou a necessidade, converte-se em algo tipificado nos dias atuais, para o direito moderno na sua expansão socializadora.

Mas há uma verdade, em que a doutrina é bastante segura: todos os ordenamentos jurídicos que admitem a figura da fundação outorgam sua proteção à vontade do fundador, para garantir não só o cumprimento das suas finalidades, mas para reconhecer na vontade do fundador a norma suprema da fundação. ${ }^{46}$

Fora de tal verdade, não existe outro caminho para a Administração, em consonância com a ordem jurídica institucional. Está certo que o fim objetivado pelas fundações venham claramente marcado pela condição de inalterabilidade. Mas a inalterabilidade desse fim não é nunca absoluta. Seria gravemente prejudicial para a fundação se assim o fosse. As circunstâncias que mudam podem obrigar necessariamente a novas adaptações, sem quebra da fidelidade à vontade do fundador ao constituir a fundação. ${ }^{47}$

Não há, portanto, um critério rigorosamente exato, quanto à evolução do fim e o caráter permanente das fundações. Não havendo um critério exato, permite-se às fundações, em razão do ordenamento jurídico, que assumam em qualquer tempo ou momento da criação, finalidade que melhor digam com a pretensão do Estado, sempre sensível a fatos essenciais novos que buscam racional entendimento e formulação. ${ }^{48}$

Justificando-se a fundação-empresa, no Estado moderno pressionado por tantas exigências, vale sobretudo o princípio tradicional que reconhece a vontade do instituidor como a lei que rege a fundação. Para tipificar a fundação, com forma de empresa, basta a presença do fim da atividade empresarial, conforme as diretrizes impostas pelo fundador no ato de cria̧̧ão. A adequação à atividade econômica ordenada estatutariamente reflete elementos definidos com titularidade jurídica imediata.

46 Valero Agundez - ob. cit., pág. 28.

47 Urbano Valero Agundez - ob. cit., págs. 31/33.

48 Caracter de las normas del Derecho de la fundación - Agundez ob. cit., págs. $64 / 5$. 


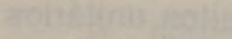
4.

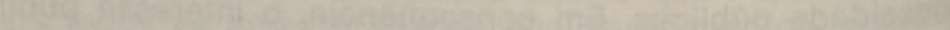

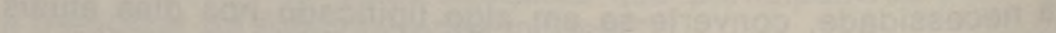

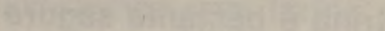

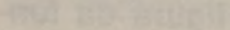

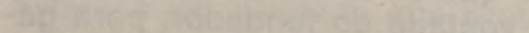

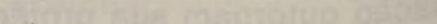

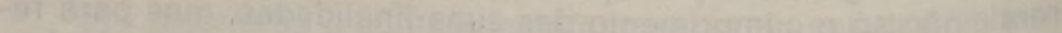
69.

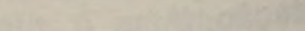

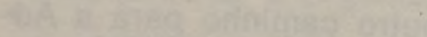

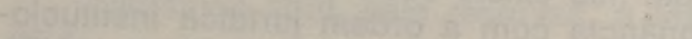

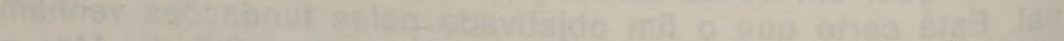
G.

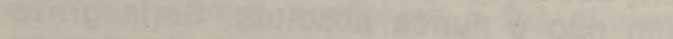
Whif

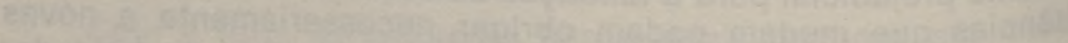

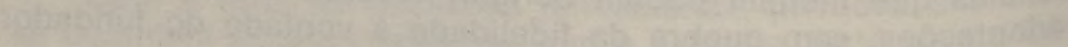

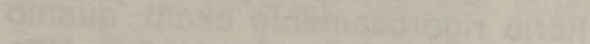

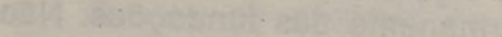

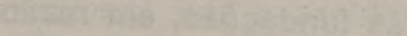
(b)

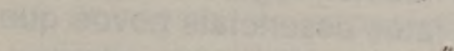

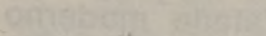

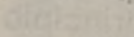

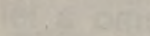

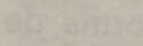
5.

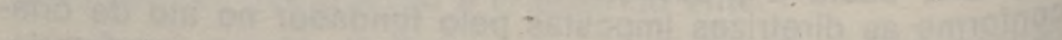

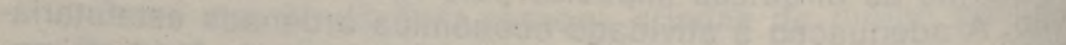
-

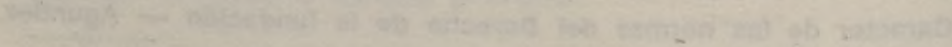

